\title{
A.JO'ГE
}

African Journal of Teacher Education

ISSN 1916-7822. A Journal of Spread Corporation

Vol.7 No. $3 \quad 2018 \quad$ Pages $50-63$

\section{Teacher Characteristics that Influence Development of Oral Language Skills among Pre-Primary School Pupils in Nairobi City County, Kenya.}

\author{
Kenneth Odhiambo Okelo, \\ Esther Waithaka \& Maureen Mweru
}

Kenyatta University

\begin{abstract}
This article presents the findings from our investigation of teachers' characteristics that influence development of oral language skills among pre-primary pupils. The study was conducted in 83 schools in Kibra sub-county, Kenya. Questionnaires and observation schedules were used to collect data. Data was analysed using SPSS. The main findings of the study indicate that teaching strategies that were mostly used by pre-primary school teachers were code-switching, examples, repetition, substitution and explanation. On the other hand, questions, direction, expansion of children words and contrast were the least used teaching strategies when teaching oral language skills. The study revealed that the there is a slight correlation between the type of training teachers received and the teaching strategies they used as most of the DICECE (District Centres for Early Childhood Education, Kenya) trained teachers used more teaching strategies when teaching oral skills compared to non-DICECE teachers. The findings also revealed that there was some correlation between teacher's academic qualifications and their use of a few teaching strategies. There was also some correlation between teaching experience and the use of a few teaching strategies. Since the strategies used by pre-primary school teachers under the study were less than half of the recommended teaching strategies to promote oral skills, the study recommends that teachers should be encouraged to use more in structural strategies to improve children's oral language skills.
\end{abstract}

Keywords: oral language skills acquisition, Kenya education, Kenya preschool, Kenya early childhood education, preschools, teaching methods and determinants. 


\section{Introduction}

Development of oral language skills is a precursor to writing and reading acquisition. According to Yaman (2007), this implies that supporting oral language skills in early childhood will promote better performance in literacy. Atkinson (2011), assert that supporting oral language skills in early and later childhood contributes to better development in comprehension skills in later years. Similarly, oral language skills have also been found to be leading to effective learning of vocabulary and comprehension skills (Chowdhury, Raqib, and Phan, 2008). In view of expected long term benefit of early oral language skills acquisition, there was need to focus on oral language skills to boost the compression skills for children.

Hall, Quinn and Gollnick (2014) argue that, oral language competency forms the foundation for reading, writing as well as for learning in other activity areas. Children find it much easier than adults to acquire oral language skills because of their high adaptation capacity. The pre-primary school years are crucial for the development of children's oral language (Cummins, 2007). Bang (2003) ascertains that remarkable and rapid developments in spoken language take place during the preprimary school years. Given the importance of oral language skills in developing language, researchers have sought to identify and evaluate teachers' interaction styles. Pre-primary school teachers, who guide the child's attention, lead those who label, describe, or comment upon objects, actions or events to which the child is currently attending are generally facilitative of children's oral language development (Atkinson, 2011). On the other hand, pre-primary teachers with more directive, responding styles that seek to control children's communicative behaviour and to change their focus of attention inhibit development of oral skills.

Athiemoolam (2004) opines that appropriate teaching strategies enhance oral language skills development. Studies by Atkinson, 2011 in UK; Bang, 2003 in South Korea; Chowdhury, Raqib, and Phan, 2008 in Bangladesh identified some appropriate instructional strategies that promote oral language skills development among pre-primary school children. These include role play, scaffolding, repeating, giving contrasting words and phrases, giving examples, substituting words and phrases with learning materials, expanding on what has been said by children, asking questions, explaining words and phrases, code-switching and giving direction as appropriate when teaching oral language at the pre-primary school level. However, factors such as teachers' training, experience, and academic 
qualification have been cited to be the major factors influencing the use of the above teaching strategies (Chowdhury, Raqib, and Phan, 2008).

Brown (2001) in his study on approaches used by teachers to teach English language in New York suggests that teachers should make time and develop the confidence and skills to hold conversation with young children regularly through books, songs, stories, and experiences. Brown argues that, using children's interests as a basis for conversation, teachers should speak courteously to children and plan or take advantage of spontaneous opportunities to talk with each child informally. They should also refrain from talking judgmentally about children or others to them or in front of them, show affection and sincere interest in children, and send consistent verbal and non-verbal messages. In addition, he urged that teachers should invite children into extended conversations with peers and adults and listen attentively to what children have to say. However, most teachers in Kenya often ignore the child's mother tongue as they use a second language (English in Kenya) as the medium of instruction when teaching oral language skills (Harrow and Mpoche, 2008).

According to Breen and Candlin (2001), second languages (English, French, German, Spanish, and Italian among others) are the most used language in primary schools in Europe, Asia, and America. These second languages are used for instruction and assessment of all subjects. Most children are expected to have achieved second language competency as early as their entry in preschool despite the fact that most families use their first language at home. This trend is similar in African countries where the language of instruction and national language is inherited from colonial rulers. For example, in most West and Central African countries, French is the main language while East, South and North African countries use English and Portuguese. According to Owólabí, Dasylva and Banjo (2004), the Nigerian Ministry of Education has incorporated such languages into the National School Curriculum. Athiemoolam (2004) also notes that, second languages have taken central stage in teachers' training and children's teaching. This study therefore, strived to find out whether teachers' characteristics influence their use of appropriate teaching strategies in developing oral language skills among preprimary school children in Kenya.

Studies carried out in Kenya have recommended the use of the language of the catchment area or mother tongue as the medium of instruction (GoK, 2000; Mwathe, 2003; Odera, 2011). This is important because young children first come to school familiar only with their mother tongue or a language spoken in their home environment. The Kenya Primary School Curriculum by the Kenya 
Institute of Curriculum Development (KICD) emphasizes the importance of English language as both a compulsory and examinable subject (Odera, 2011). The primary school English syllabus postulates that fluency in all aspects of the English language will enable children to perform better in all other subjects whose medium of instruction is English (KIE, 2006). This therefore, suggest that teachers should adopt appropriate methodology that enhances children's listening and speaking skills in the language of instruction so as to enable children to perform better in all activity areas.

A study conducted by Karanu (2002) on production and use of resources for English language found that all the schools in Kibra use English and Kiswahili as the language of interaction. From her findings, the least used instructional strategies in teaching English language were expanding on children's words and phrases and using contrasting items (providing opposites of words and phrases). She also observed that contrasting items, explaining, giving examples, and expanding on children's sentences were never used. Inappropriate teaching strategies hinder acquisition of oral language skills (Mwangi, 2007). These necessitate studies on the reasons why teachers are not employing such better teaching strategies. This study therefore, intends to find out teachers' factors influencing their choice of strategies in development of oral language skills inside and out of classroom.

\section{Objectives of the Study}

This study was guided by the following objectives:

i. To establish the strategies teachers use to develop oral language skills among pre-primary school children in Kibera sub-county

ii. To determine the relationship between training and strategies teachers use to develop oral skills among pre-primary school children in Kibera Sub-County.

iii. To determine the relationship between teachers' experience and the strategies they use in developing oral language skills among pre-primary school children in Kibera Sub-County.

iv. To find out the relationship between teacher's academic qualification and the strategies teachers use to develop oral language skills among pre-primary school children in Kibera Sub-County.

\section{Methodology}

This study employed descriptive survey design. According to McRoy (2009), descriptive survey design involves either identifying the characteristics of an observed phenomenon or exploring possible correlation among two or more phenomena. This research design is suitable for this study as it allows 
investigations of issues at hand in detail as well as finding the correlations among them. The design enabled the researcher to gain a deep insight of the pre-primary teachers' characteristics such as their training, experience and academic qualifications. Then correlate them with the strategies pre-primary school teachers use to promote development of oral language skills among children in Kibra SubCounty.

Thus, this study involved in-depth repeated observations of pre-primary school teachers to establish any significant relationship between type of training, teaching experience and academic qualifications and the ways in which they use instructional strategies in teaching oral skills. This study used qualitative and quantitative methods. Qualitative data was collected through self- administered questionnaires to pre-primary school teachers. While quantitative data was obtained through observation checklists. The researcher adopted this strategy since it captures both qualitative and quantitative data, which could otherwise have been lost if only one method was, used (McRoy, 2009).

\section{Sampling Techniques}

The researcher used multistage sampling technique to come up with the sample of this study. Multistage sampling strategy involves sampling in two or more stages (Gerhardt, 2004). In the first sampling stage, Kibera Sub-County was purposively selected out of 15 Sub-Counties in Nairobi County since most of the teachers used few instructional strategies as pointed out by Karanu (2002). At the second stage, all the eight public pre-primary schools were purposely selected since they are few in number. The third stage was to use stratified random sampling to select private pre-primary schools whereby all of them had equal chances of being selected (McRoy, 2009). Wards was used as the strata and from the five wards of Woodley, Sarangómbe, Makini, Lindi, and Laini Saba, a sample of 75 private pre-primary schools was obtained. After determining the sample of schools to be used, one teacher from each school was randomly selected to ensure that only pre-primary teachers were included as respondents for this study.

\section{Data Collection Techniques}

In order to obtain data on the strategies used by the pre-primary school teachers, the researcher administered questionnaires to pre-primary school teachers from the sampled schools. Selfadministered questionnaires were applicable since teachers were to read and fill the questionnaires. In addition, in each school the researcher observed one teacher during the lessons. The researcher sat in the classroom during the lesson to observe the number of times each teacher used the six teaching 
strategies (repetition, substitution, explanation, contrast, exemplification and code-switching). Each teacher was observed five times in one day. Each observation lasted for ten minutes.

\section{Data Analysis}

The researcher carried out descriptive analysis on the qualitative data collected. Data from open-ended questions in the questionnaires was categorized into themes and analysed respondents' views on teaching strategies used in developing oral language skills in pre-primary school children. While data from closed ended questions was coded and analysed numerically. Responses from the participants on part B and C of the research instrument (questionnaire) was coded. The coded data was directly entered in the Statistical Package for the Social Sciences (SPSS) which is a computer package used in analysing data. Frequencies of responses were computed into percentages and presented in bar charts and tables. Chi square test was used to determine the association between variables.

\section{Findings}

\section{Strategies Pre-primary School Teachers Use in Teaching Oral Language Skills}

Through the use of observation checklist, data was collected in a 3-point Likert scale. The data was analysed through Means, Standard deviation and skewness. According to the scale, a mean of 2.5 and above represented 'Always', 1.5-2.4 represented 'sometimes' and less than 1.5 'never'. The standard deviation (SD) was used to determine the level of variability of the responses. A SD of less than 1.0 indicated less variability (consensus) and a SD of more than 1.0 indicates more variability and lack of consensus.

Table 4.1 Mean Frequency of Strategies Teachers Uses in Teaching Oral Skills

\begin{tabular}{|c|c|c|c|c|c|c|c|}
\hline & $\mathrm{N}$ & Min & Max & Mean & Std. Dev & Skewness & St. Error \\
\hline Code-switching & 83 & 2 & 3 & 2.96 & 0.19 & -5.06 & 0.26 \\
\hline Examples & 83 & 2 & 3 & 2.92 & 0.28 & -3.05 & 0.26 \\
\hline Repetition & 83 & 2 & 3 & 2.88 & 0.33 & -2.38 & 0.26 \\
\hline Substitution & 83 & 2 & 3 & 2.86 & 0.35 & -2.06 & 0.26 \\
\hline Explanation & 83 & 1 & 3 & 2.65 & 0.53 & -1.15 & 0.26 \\
\hline Questions & 82 & 2 & 3 & 2.60 & 0.49 & -0.41 & 0.27 \\
\hline
\end{tabular}


Teacher Characteristics that Influence Development of Oral Language Skills among Pre-Primary School Pupils in Nairobi City County, Kenya

\begin{tabular}{|l|r|r|r|r|r|r|r|}
\hline Directing & 83 & 2 & 3 & 2.55 & 0.50 & -0.22 & 0.26 \\
\hline Expansion & 83 & 1 & 3 & 2.29 & 0.60 & -0.19 & 0.26 \\
\hline Contrasts & 83 & 1 & 3 & 1.80 & 0.73 & 0.34 & 0.26 \\
\hline
\end{tabular}

\section{KEY: 1=Never, 2=Sometimes, 3=Always}

Table 4.2 shows that, the most frequently used method when teaching was code-switching $(\mathrm{M}=2.96)$ followed by exemplification ( $\mathrm{M}=2.92)$ and thirdly repetition $(\mathrm{M}=2.88)$. The above data indicates that on average most teachers used all the above strategies when teaching. Other strategies the teachers sometimes used when teaching included substitution $(\mathrm{M}=2.86)$, explanation $(\mathrm{M}=2.65)$, use of questions $(M=2.60)$ and use of directing strategies $(M=2.55)$. The results show that expansion $(M=2.29)$ and contrast $(\mathrm{M}=1.8)$ strategies were least used by the teachers. The values of the skewness in all the variables except contrast were negative indicating that most of the teachers always used the strategies when teaching. Contrast was positively skewed showing that most of the teachers did not use the method.

Studies reviewed in the literature also point out such commonly used strategies to promote oral language skills by pre-primary school teachers (Atkinson, 2011; Bang, 2003; Chowdhury, Raqib, and Phan, 2008). Mitchell, (2008) and Gains \& Redman (1990) established in their study that most teachers used at least six instructional strategies while Fillmore (2005) and Richards \& Rodgers (2005) found that most teachers used three instructional strategies. However, the teachers in the present study reported use of more instructional strategies than featured in the literature reviewed. This could be associated with the demographic of the teachers in the present study, most of who had more than six years' experience and have a diploma in early childhood education (ECD) training.

\section{Teachers Training and Strategies for Teaching Oral Skills}

The second objective was to establish the association between the type of teacher training and the use of teaching strategies for oral language skills. The researcher tested the association between types of training and the teaching strategies using independent chi square test and the results presented in Table 4.2 . 
Table 4.2 Chi-square Test between Training and Teaching Strategies

\begin{tabular}{|l|r|r|r|}
\hline & Chi value & Df & \\
\hline Substitution & 0.578 & 2 & 0.749 \\
\hline Contrasts & 7.535 & 4 & 0.110 \\
\hline Explanation & 26.971 & 4 & 0.000 \\
\hline Repetition & 2.585 & 2 & 0.275 \\
\hline Examples & 0.312 & 2 & 0.856 \\
\hline Code-switching & 0.151 & 2 & 0.927 \\
\hline Expansion & 0.944 & 4 & 0.918 \\
\hline Questions & 2.861 & 2 & 0.239 \\
\hline Directing & 1.722 & 2 & 0.423 \\
\hline
\end{tabular}

From the results in Table 4.4, there is a significant $\left(\chi^{2}(2)=26.971, \mathrm{p}<0.05\right)$ association between type of teacher training and the use of explanation as teaching strategy. That is, most DICECE trained teachers used explanation strategy as compared to their counterparts who had attended other types of training. However, other strategies such as substitution, contrasts, repetition, examples, codeswitching, expansion, questions and directing did not show significant association with the type of teacher training.

From this study, use of the teaching strategies were similar across the three types of training programs (DICECE, KHA (Kindergarten Headmistresses' Association Kenya) and University) and untrained teachers. This may suggest some basic similarity of these teacher training programmes regarding the teaching strategies used to promote development of oral language skills among preprimary school children. These results agree with the rest of the findings in the study that all preschool teachers' use of the various teaching strategies in teaching oral language skills was similar across the different types of trainings. Ng'asike (2004) in his study of the use of play as a medium for bridging preschool children's mathematical experiences in Kasarani Division, also found no significant association between the type of training and teaching strategies. This could be due to similarity in 
training curriculum in all the training types since the Kenyan ministry of education harmonises curriculum of all the training institutions.

This implies that the type of training a teacher underwent did not impact their choice of appropriate teaching strategy. Mwangi (2007), in her study on the use of oral instructional strategies in teaching English in Kasarani, established that when new teachers are recruited, they tend to adapt to the teaching strategies being used by the teachers in that school. This might explain the insignificant association between the type of training and appropriate teaching strategies that promote development of oral language skills among pre-primary school children. Similarly, a study by Nguyen and Khuat (2012) on effectiveness of learning vocabulary through games in Asia established association between teacher training and the English language teaching methods. In addition, they advanced the importance of ensuring effective training of teachers for the provision of quality education. Since during such trainings teachers develop professional attitudes, skills and knowledge to adapt to the teaching and learning environment.

However, the current study finding contradicts the study by Mitchell (2008). According to Mitchell's study (2008) on communicative language teaching practice in London, teachers who used more appropriate teaching strategies were found to have undergone adequate teacher trainings. Therefore, they were able to engage children in learning and sustain their interests through the use of multiple strategies. Such variations witnessed between Mitchell's study and the current study could be attributed to the fact that most pre-primary schools in London do not employ untrained teachers (Mitchell, 2008). The findings from the current study indicates inadequate use of appropriate strategies by teachers across all types of training in the teaching of oral language skills in Kibra sub-county. The inadequacy of appropriate teaching strategies when teaching oral skills is likely to affect the academic performance of pre-school children in the sampled population. It is important for teachers to use several strategies when teaching children oral language skills (Richards and Rodgers, 2005). This is observed despite the importance of oral skills as a precursor to writing, reading acquisition and learning in different activity areas in pre-primary schools sampled in this study.

\section{Teacher's Experience and Strategies used for Teaching Oral Skills}

The third objective was to establish the association between teachers' teaching experience and the use of teaching strategies. To determine the association between the teacher's experience and the usage of 
various teaching strategies, the researcher used chi square test and the results were presented in Table 4.3 .

Table 4.6 Chi Square Test between Experience and Teaching Strategies

\begin{tabular}{|l|r|r|r|}
\hline & Chi value & Df & Sig \\
\hline Substitution & 6.623 & 8 & 0.578 \\
\hline Contrasts & 22.617 & 16 & 0.124 \\
\hline Explanation & 26.280 & 16 & 0.049 \\
\hline Repetition & 5.014 & 8 & 0.756 \\
\hline Examples & 10.145 & 8 & 0.255 \\
\hline Code-switching & 10.761 & 8 & 0.216 \\
\hline Expansion & 26.663 & 16 & 0.045 \\
\hline Questions & 10.086 & 8 & 0.259 \\
\hline Directing & 9.015 & 8 & 0.341 \\
\hline
\end{tabular}

Table 4.6 shows a significant association between explanation strategy $\left(\chi^{2}(16)=26.280, p<0.05\right)$ and teacher's experience. Similarly, the study also shows a significant association between expansion strategy $\left(\chi^{2}(16)=26.263, \mathrm{p}<0.05\right)$ and the teachers experience. However, other strategies such as substitution, contrasts, repetition, examples, code-switching, questions and directing did not show significant association with the teacher's experience. These findings, therefore, imply that the more experience a teacher has the more likely he/she will use expansion and explanation teaching strategies while teaching. The findings from the current study agree with other findings by Nyangeri (2014) on determinants of pre-primary school teachers' use of music as a medium of instruction in Kitale municipality. In her findings Nyangeri (2014), established that teaching experience influences teachers use of music as a medium of instruction.

However, the current study also shows that there is no significant association between teachers' experience and other teaching strategies. This is consistent with a study by Mwangi (2007) on the use of oral instructional strategies in teaching English in Kasarani which indicates that teachers adopt teaching strategies they find being used in schools they are teaching at. However, the use of such 
Teacher Characteristics that Influence Development of Oral Language Skills among Pre-Primary School Pupils in Nairobi City County, Kenya

limited teaching strategies could in turn negatively affect children's acquisition of oral skills and could lead to poor academic performance.

\section{Teachers' Academic Qualifications and Strategies used in Teaching Oral Skills}

The fourth objective was to establish the relationship between teacher's academic qualification and the use of appropriate teaching strategies to promote development of oral language skills. To determine the association between the teacher's academic qualifications and the usage of various teaching strategies, the researcher used chi square test and the results were presented in Table 4.4.

Table 4.4. Chi Square Test between Qualifications and Teaching Strategies

\begin{tabular}{|l|r|r|r|}
\hline & Chi value & Df & Sig \\
\hline Substitution & 2.242 & 2 & 0.326 \\
\hline Contrasts & 7.430 & 4 & 0.115 \\
\hline Explanation & 6.306 & 4 & 0.177 \\
\hline Repetition & 4.837 & 2 & 0.089 \\
\hline Examples & 2.859 & 2 & 0.239 \\
\hline Code-switching & 0.164 & 2 & 0.921 \\
\hline Expansion & 11.441 & 4 & 0.022 \\
\hline Questions & 0.992 & 2 & 0.609 \\
\hline Directing & 5.814 & 2 & 0.055 \\
\hline
\end{tabular}

Table 4.8 shows a significant association between expansion $\left(\chi^{2}(4)=11.441, \mathrm{p}<0.05\right)$ and the teacher's academic qualification. However, other strategies such as substitution, contrasts, explanation, repetition, examples, code-switching, questions and directing did not show significant association with the teacher's academic qualification. These findings on the use of substitution, contrasts, explanation, repetition, examples, code-switching, questions and directing strategies agree with other studies. The studies by Mwangi (2007) and Nyangeri (2014) indicate that there is no significant correlation between teacher's academic qualification and the teaching strategies. However, the current study also found out that teachers' academic qualification influences the use of expansion when teaching children oral language skills. 
On the other hand, the finding on expansion which showed a significant association with academic qualification agree with the findings by Umar-ud-Din, Khan and Mahmood (2010). According to the study by Umar-ud-Din, Khan and Mahmood on the effects of teachers' qualification on students' second language performance at the secondary level in USA, teachers with Formal Education (ELTs) had positive influence on the performance of the students in the final examinations.

\section{Recommendations}

The findings revealed that not all teachers were using appropriate teaching strategies to promote pupil's oral skills. The National Centre for Early Childhood Education (NACECE) should ensure pre-primary school teacher trainees in DICECEs and other training institutions are trained on appropriate teaching strategies used to promote oral skills development. This will assist teachers to gain knowledge and skills on such strategies. This will offer them with a wide variety of teaching strategies to choose from while teaching oral skills. Pre-primary school teachers should also be given refresher courses on the emerging teaching strategies that promote development of oral language skills.

The results indicated that there was a significant association between teacher's experience and the use of some teaching strategies. However, from the findings of this study most pre-school teachers have less than five years' experience. The school managements should come up with strategies to hire and retain experienced teachers in pre-primary schools to improve the use of appropriate teaching strategies.

The findings also established association between the use of a few teaching strategies such as expansion and teacher's academic qualifications. From the study, about three quarter of the teachers sampled are currently trained up to diploma level. This therefore, implies that more than a quarter of the pre-primary school children in Kenya are taught by untrained teachers. The school managements should ensure that they only recruit trained teachers according to the ECD (2008) standard guidelines.

\section{References}

Athiemoolam, L. (2004). Drama-In-Education and Its Effectiveness in English Second/Foreign Language Classes. In the First International Language Learning Conference(ILLC).

Atkinson, D. (2011). Alternative approaches to second language acquisition. London: Routledge.

Bang, Y. (2003). Developing communicative competence through drama-oriented activities in an EFL classroom. Myongji University. 
Teacher Characteristics that Influence Development of Oral Language Skills among Pre-Primary School Pupils in Nairobi City County, Kenya

Breen, M.P. \& Candlin, C.N. (2001). The Essentials of a Communicative Curriculum in Language Teaching. In Innovation in English Language Teaching. London and New York: Routledge in association with Macquarie University and The Open University.

Brown, H. D. (2001). Teaching by principles: An interactive approach to language pedagogy. White Plains, NY: Longman.

Chowdhury, Raqib, \& Phan Le Ha. (2008). Reflecting on Western TESOL Training and Communicative Language Teaching: Bangladeshi Teachers' Voices. Asia Pacific Journal of Education 28 (3), 305-16. doi:10.1080/02188790802236006.

Cummins, J. (2007). International handbook of English language teaching. New York: Springer.

Fillmore, L. (1985). Second language learning in children: A proposal model. In REshch \& Provinzano (Eds.), Issues in English language development. Roslyn, VA: National Clearinghouse for Bilingual Education.

GoK, (2000). Guidelines for early childhood development in Kenya. Nairobi: KIE/NACECE.

Hall, G. E., Quinn, L. F. \& Gollnick, D. M. (2014). Introduction to teaching: Making a difference in student learning.

Harrow, K. W. \& Mpoche, K. (2008). Language, literature and education in multicultural societies: Collaborative research on Africa. Newcastle, UK: Cambridge Scholars Pub.

Karanu, N. J. (2002). Training in production and use of resources for English language teaching in selected Nairobi lower primary schools. Unpublished M. Ed Thesis, Kenyatta University.

McRoy, R.G. (2009). Qualitative research. Thousand Oaks, CA: Corwin Press.

Mitchell, R. (2008). Communicative language teaching in practice. London: CLT.

Mwangi, M. W. (2007). Pre-school teachers' use of oral instructional strategies in teaching English: a study in Kasarani division, Nairobi province. Unpublished Master Theses, Kenyatta University.

Mwathe, G. N. (2003). English second language (L2) literacy instruction and acquisition in Kenyan rural primary schools: A thesis submitted in partial fulfilment of the requirements for the degree of M. Ed. (Special Education), Massey University, Palmerston North, New Zealand

AJOTE Vol. 7. No. 3. (2018), 50-63. 
Ng'asike, T. (2004). Teachers' use of play as a medium for bridging preschool children's mathematical experiences. Kasarani Division, Nairobi, Kenya. Unpublished M. Ed Thesis, Kenyatta University

Nguyen, T. \& Khuat, T. (2012). Learning Vocabulary through Games: The Effectiveness of Learning Vocabulary through Games. Asian EFL Journal 1 (2): 4-16.

Nyangeri E. J. (2014). Determinants of pre-primary school teachers' use of music as a medium of instruction in Kitale municipality, Trans-Nzoia County, Kenya. Unpublished M. Ed Thesis, Kenyatta University.

Odera, F. Y. (2011). Learning English Language by Radio in Primary Schools in Kenya. New York: David Publishing.

Owólabí, K., Dasylva, A. O., \& Banjo, L. A. (2004). Forms and functions of English and indigenous languages in Nigeria: A festschrift in honour of Ayo Banjo. Ibadan: Group Publishers.

Richards, J. \& Rodgers, T. (2005). Approaches and methods in language teaching. A descriptive analysis. New York: Cambridge University press.

Yaman, M.B. (2007). Crossing Borders: Drama in the Second Language Classroom. Saarbrucken, Germany: VDM Verlag. 